\title{
LA INTERSUBJETIVIDAD EN LA TEORÍA TRASCENDENTAL DEL CONOCIMIENTO
}

\author{
ANTONIO M. LÓPEZ MOLINA \\ Universidad Complutense de Madrid
}

\begin{abstract}
RESUMEN: Este trabajo tiene como objeto fundamental llevar a cabo una reconstrucción de la teoría trascendental del conocimiento en las experiencias filosóficas de Kant y Habermas. En ambas se produce un peculiar tránsito de la subjetividad a la intersubjetividad, gracias al cual se rompe el paradigma de la filosofía de la conciencia y emerge una específica experiencia comunicativa a través del sensus communis y de la razón comunicativa. A lo largo de esta investigación se intenta poner de manifiesto el paralelismo entre ambos proyectos filosóficos, cuyo fundamento es la ilustración o la autonomía de la razón. Subjetividad trascendental, sensus communis, intereses del conocimiento y razón comunicativa representan distintas soluciones al problema de la comunicabilidad de los juicios mediante los que declaramos la posibilidad, realidad y necesidad de los estados de cosas.
\end{abstract}

PALABRAS CLAVE: Subjetividad trascendental; sensus communis; intereses del conocimiento; intersubjetividad; razón comunicativa; Kant; Habermas.

\section{Intersubjectivity and transcendental theory of knowledge}

ABSTRACT: This paper has a main objective: a reconstruction about the transcendental theory of knowledge in the philosophical experiences of Kant and Habermas. In respective works something similar happen, specifically structures of knowledge from Subjectivity to Intersubjetivity. In this way both authors break the Paradigm of Consciousness, and appear a specific communicative experience thought Sensus Communis, and Communicative Reason. This research focuses on the parallelism between two philosophical systems, whose foundation is the Enlightenment or the autonomy of reason. Transcendental Subjectivity, Sensus Communis, Knowledge and Human Interests, and Communicative Reason represent different solutions to the problem of communicability of the judgments through which declare the possibility, reality, and necessity of the states of affairs.

KEY WORDS: Transcendental Subjectivity; Sensus Communis; Knowledge and Human Interests; Intersubjectivity; Communicative Reason; Kant; Habermas.

El punto de partida de nuestra meditación es el siguiente: el factum de las ciencias y del mundo de la vida, el progreso técnico-científico y muchos de los objetivos cumplidos en el ámbito del Derecho, en el ámbito de la Moral y en el ámbito de lo social, nos tienen que servir de orientación para rechazar de entrada cualquier opción que juegue con la mirada escéptica. Como se nos dice en el $\S 21$ de la Crítica del Juicio: "Conocimientos y juicios, juntamente con la convicción que les acompaña, tienen que poderse comunicar universalmente, pues de lo contrario no tendrían concordancia alguna con el objeto: serían todos ellos un simple juego subjetivo de las facultades de representación, exactamente como lo quiere el escepticismo» ${ }^{1}$.

1 Kritik der Urteilskraft. Herausgegeben von K. Vorländer. Verlag von F. Meiner. Hamburg 1974. § 21, 65. (A. K., V 238). [En adelante $K U$ ]. La paginación corresponde a la original en su tercera edición. Se sigue la traducción de Manuel García Morente: Crítica del Juicio, Espasa Calpe, Madrid 1975. Es este uno de los múltiples textos de Kant en el que se opone claramente al escepticismo. De cualquier modo, el estadio escéptico sólo puede ser aceptado 
Rechazamos, pues de entrada, cualquier opción escéptica. De ahí que la cuestión primordial sea la siguiente: ¿Cuál es el fundamento de la comunicabilidad de nuestros juicios, ya sean en el mundo de la vida o en el mundo de las ciencias? La respuesta a esta pregunta deseo llevarla a cabo desde dos experiencias filosóficas que, con una distancia de doscientos años, sin embargo, tienen en sí mismas tantas semejanzas en su planteamiento, nudo y desenlace, que nos impulsan a reflexionar sobre los diferentes ejes que vertebran la solución del problema. Me refiero específicamente a Kant y Habermas. Ambos profesan su experiencia filosófica en un ambiente de búsqueda de la Ilustración. Kant culmina el siglo de la diosa razón con su racionalidad trascendental, y Habermas, desde la década de los cincuenta del pasado siglo, ha intentado reconstruir el fracaso de la Ilustración proclamando la vuelta a una concepción de la racionalidad que esté a la altura de los tiempos. Ambos pensadores recorren un itinerario muy semejante, que va desde la subjetividad a la intersubjetividad, es decir, desde el yo trascendental al nosotros comunitario, desde la filosofía del sujeto a la comunidad de pensamientos y juicios.

El tránsito que Kant lleva a cabo desde la Crítica de la razón pura (subjetividad trascendental) a la Crítica del Juicio (sentido común lógico y sentido común estético) es muy semejante al que doscientos años después va a recorrer Habermas desde la materialización del sujeto trascendental en términos de intereses del conocimiento, llevado a cabo en Conocimiento e interés, a la construcción de una teoría de la razón comunicativa, gracias al giro lingüístico, desarrollada en los textos de la Teoría de la acción comunicativa y culminada en Verdad y justificación, texto que yo considero la segunda parte de Conocimiento e interés.

Planteada así la cuestión, este trabajo tendrá cuatro apartados y una conclusión:

1. Planteamiento de la Subjetividad trascendental en la Crítica de la razón pura.

2. Tránsito de la subjetividad trascendental a la intersubjetividad, guiado por los razonamientos de la Crítica del Juicio en cuanto Crítica del gusto.

3. Materialización de la subjetividad trascendental en términos de intereses del conocimiento, según los textos de Conocimiento e interés.

4. Tránsito de la teoría de los intereses del conocimiento, experiencia filosófica construida en términos de filosofía de la subjetividad, a una teoría de la intersubjetividad construida bajo la forma de una teoría de la razón comunicativa.

como un estadio de descanso de la razón en su uso dogmático, para poder después seguir avanzando en la experiencia crítica: «El escepticismo es, pues, un punto de descanso para la razón humana, donde puede reflexionar sobre su marcha dogmática y trazar un esquema del lugar donde en que se halla, con vistas a poder elegir su futuro camino con mayor seguridad, pero no un sitio de residencia permanente. Semejante lugar solo se encuentra en una certeza completa, sea del conocimiento de los objetos mismos, sea de los límites en los que se halla encerrado todo nuestro conocimiento de objetos». (Crítica de la razón pura. Trad. Pedro Ribas, Ed. Alfaguara, Madrid 1978, KrV A761/B789). 
Finamente, en la conclusión intentaré poner de manifiesto las ventajas que presenta una teoría de la razón comunicativa.

\section{Planteamiento de la subjetividad trascendental en la CRítica de la Razón pura}

Una de las claves interpretativas de la Crítica de la razón pura es la dialéctica que se produce en la experiencia filosófica kantiana entre realismo empírico e idealidad trascendental. Tal dialéctica pone de manifiesto que el realismo empírico hace referencia al hecho de que hay algo fuera del sujeto que es preciso conocer, pero que sólo podemos conocerlo si esa realidad es elaborada por la idealidad de la conciencia. Si procediésemos simplemente a recibir los datos externos desde el punto de vista de la conciencia subjetiva, estaríamos en el ámbito del realismo, o del idealismo empírico, lo cual nos conduciría irremisiblemente al escepticismo.

Por el contrario, para el idealismo trascendental las condiciones de posibilidad de la experiencia objetiva se presentan como elementos aprióricos en torno a los cuales el sujeto configura el conocimiento de la realidad. Del mismo modo que las hipótesis y las teorías abren el espacio de las ciencias físico-matemáticas, la acción espontánea de la conciencia es la que hace posible la objetividad en el ámbito del conocimiento. Si no hubiese una elaboración ideal por parte de la subjetividad, no sería posible deletrear los fenómenos y convertirlos en experiencia. En ello consiste la revolución kantiana en el modo de pensar, el llamado giro copernicano. Sólo podemos explicar la ciencia y la experiencia en general si suponemos que los objetos se acomodan a nuestras formas de conocimiento. Pero no se trata de una acomodación real, sino que la conciencia es una acción ideal que no modifica realmente el mundo, sino sólo su sentido. Los objetos no se acomodan a las idealidades aprióricas de la conciencia como el bronce a su molde, sino que los objetos son estructurados idealmente. El yo al que se acomodan los objetos no es un yo empírico, sino el yo trascendental; de lo contrario, sólo conoceríamos nuestras propias ocurrencias privadas ${ }^{2}$.

El sujeto trascendental es acción y conciencia de esa acción. No es una sustancia que exista previamente y que después se ponga a actuar (Descartes), ni tampoco es una estructura previa innata (Leibniz); no es algo inmanente al mundo (el yo empírico del empirismo), ni tampoco algo trascendente (el Dios de la Teología natural), sino que el sujeto trascendental es Autoconciencia. Son las idealidades que esa acción subjetiva proyecta para la construcción del conocimiento, pues «aunque todo conocimiento empiece con la experiencia, no

2 Entre nosotros ha desarrollado este tema con especial éxito Jacinto Rivera de Rosales en El punto de partida de la metafísica transcendental. Un estudio crítico de la obra kantiana. Ed. UNED, Madrid 1993, pp. 27-53. Igualmente este problema aparece analizado en su obra I. Kant: el conocimiento objetivo del mundo. Guía de lectura de la "Crítica de la razón pura». Ed. UNED, Madrid 1994, pp. 1-10. 
por ello procede todo él de la experiencia» ${ }^{3}$. Lo que no procede de la experiencia, que alguna vez ha sido bautizado como desconocida raíz común ${ }^{4}$, es lo que yo denomino subjetividad trascendental, que es preciso comprenderla no como un yo determinado, sino como un yo determinante, como espontaneidad, como acción originaria, gracias a la cual el conocimiento, entendido como síntesis trascendental, puede ser comunicado universalmente.

La teoría kantiana del conocimiento va a consistir, pues, en una investigación sobre el logos, en su doble dimensión intellectus et ratio, lo que dará lugar a una lógica de la verdad (Analítica trascendental) y a una Crítica de la ilusión trascendental (Dialéctica trascendental) ${ }^{5}$. Es el logos quien tiene la tarea de suministrar los contenidos puros a priori mediante los que el sujeto humano puede construir juicios comunicables acerca de la realidad en general y de la realidad empírica en particular. Corresponde a la Analítica del entendimiento puro el territorio de la verdad que en bella metáfora kantiana se describe como una isla, patria de la verdad, "rodeada por un océano ancho y borrascoso, verdadera patria de la ilusión» ${ }^{6}$.

El criterio de validez universal que diferencia claramente el lugar de la verdad de la esfera de la ilusión viene determinado por el principio supremo de todos los juicios sintéticos a priori, en conformidad con el cual «todo objeto debe hallarse sometido a las condiciones necesarias de la unidad ${ }^{7}$ que sintetiza en una experiencia posible lo múltiple de la intuición ${ }^{8}$, es decir, que los objetos reales a los que Kant llama fenómenos (Phaenomena), frente a los objetos ilusorios a los que denomina noúmenos, tienen que ser el producto, la construcción, de una singular sintesis, a saber, la unidad sintética a priori generada por la conciencia trascendental sobre la multiplicidad sensible que viene por vía de la aísthesis, por vía de la sensibilidad. De ahí que Kant dedique una parte en la Crítica de la razón pura a la ciencia de todos los principios de la sensibilidad a priori o Estética trascendental. En definitiva, el conocimiento es el resultado de un feliz acuerdo, de una concordancia perfecta entre el logos y la aísthesis, en el que tan importante es el uno como el otro. Cuando falta alguno de los dos elementos, estamos en el ámbito de lo privado, de lo incomunicable, de lo meramente subjetivo, de un saber que no tiene pretensiones de verdad 9 .

$3 \quad K r V \mathrm{~B} 1$.

4 Cfr. Martínez MarzoA, F., Desconocida raíz común. Estudio sobre la teoría kantiana de lo bello. Ed. Visor, Madrid 1987.

5 Cfr. Reguera, I., La lógica kantiana. Ed. Visor, Madrid 1989. Especialmente interesantes para este tema son las pp. 83-124.

$6 K r V$ A 236/ B 295

7 Este concepto de unidad es muy importante porque con él no se refiere Kant a la unidad concebida por los juicios de cantidad, específicamente por los juicios universales, sino que es la unidad conferida por la subjetividad trascendental.

$8 \quad K r V$ A158/B197.

9 Cfr. Palacios, J. M., El idealismo trascendental: teoría de la verdad. Ed. Gredos, Madrid 1979. Especialmente interesantes para este tema son las pp. 19-25. 
Pues bien, ese conocimiento comunicable, verdadero, que es propio de la esfera de validez universal se nos presenta en la forma de juicios sintéticos a priori, que son los únicos válidos para la construcción de las ciencias físicomatemáticas y para todo conocimiento en general. Su estructura constituye, pues, el corazón mismo de la epistemología kantiana, y es la siguiente: los juicios sintéticos a priori son el resultado de una triple síntesis en la que entra en juego todo el entramado de facultades que Kant asigna a la unidad de la conciencia. Y si bien puede todo ello tener la apariencia de un esquema algo artificioso, lo es más en su forma que en su propio contenido y resultado.

La argumentación kantiana es la siguiente: todo juicio sintético a priori es el resultado de la relación entre un conocimiento empírico-sensible con las condiciones formales de la intuición a priori, (síntesis de aprehensión), en segundo lugar con la síntesis de la imaginación productiva gracias a la cual las imágenes sensibles se transfiguran en esquemas trascendentales $\mathrm{y}$, finalmente, con la necesaria unidad producida por la apercepción trascendental y las categorías, en la que los esquemas son reconocidos como conceptos ${ }^{10}$.

Podría parecer que este esquema estaría cerca de la autorreflexión hegeliana en la que pasamos fenomenológicamente de la apariencia al concepto (ser, esencia, concepto $)^{11}$. Sin embargo, no es así, porque el juego sintético a priori entre imagen, esquema y concepto es necesario pensarlo desde una tríada circular en la que los tres elementos están en la misma posición. La síntesis última en la que se produce el conocimiento comunicable es la producida por la conciencia trascendental y la unidad sintética a priori. Ella constituye, pues, la conocida raíz común desde la cual surge la síntesis trascendental que hace comunicable nuestros pensamientos y nuestros juicios.

¿En qué consiste, pues, la subjetividad trascendental? Puesto que no nos está permitido sustancializarla, convertirla en un objeto, debemos definirla como una función, como una función lógico-trascendental mediante la que expresamos la capacidad de la naturaleza humana de «reducir conocimientos dados a la unidad objetiva de la apercepción» ${ }^{12}$. Así, cuando enuncio el juicio «Los cuerpos son pesados», no estoy relacionando dos representaciones particulares en virtud de un cierto conocimiento empírico, sino que en ese juicio las dos representaciones se hallan enlazadas en el objeto mismo, es decir, independientemente del estado del sujeto. La relación entre los dos conceptos («cuerpos»y «pesados») va más allá de la simple percepción empírica («siento

10 «Por consiguiente, el principio supremo de todos los juicios sintéticos consiste en que todo objeto se halla sometido a las condiciones necesarias de la unidad que sintetiza en una experiencia posible lo diverso de la intuición. Los juicios sintéticos a priori son así posibles cuando relacionamos las condiciones formales de la intuición a priori, la síntesis de la imaginación y la necesaria unidad de esta última síntesis en una apercepción trascendental con un posible conocimiento empírico en general». ( $K r V$ A158/B197).

11 Para el paralelismo entre la autorreflexión hegeliana y la síntesis trascendental kantiana véase el excelente libro de Charles TAYlor, Hegel. Trad. F. Castro, C. Mendiola y P. Lazo. Ed. Anthropos, Barcelona 2010, pp. 26-43.

$12 K r V \mathrm{~B} 141$. 
la pesadez de un cuerpo cuando cargo con él»). La cópula «son» hace referencia a una relación universal entre dos conceptos que en sí mismos son particulares y contingentes. De ahí que Kant pueda afirmar que «la forma lógica de todos los juicios es la unidad objetiva de apercepción de los conceptos contenidos en ellos» ${ }^{13}$. En el $§ 16$ de la Crítica de la razón pura, la subjetividad trascendental es formulada en términos cartesianos (Ich denke) e interpretada en sentido lógicotrascendental, esto es, como la función de la unidad sintética originaria:

El yo pienso tiene que poder acompañar a todas mis representaciones, pues si no, sería representado en mí algo que no podría ser pensado, lo cual significa tanto como decir que la representación sería, o bien imposible o al menos nada para mí. ${ }^{14}$

Así pues, este yo pienso no debe ser considerado en un sentido empíricopsicológico al estilo cartesiano (sentido interno en la versión kantiana), sino exclusivamente como pura actividad; en sí mismo sólo puede ser representado como la condición pura de nuestros pensamientos. El "yo pienso» no es en sí mismo ni una intuición ni un concepto, sino únicamente la conciencia que acompaña a todo concepto, la forma de todo juicio, y en consecuencia la forma de los conceptos puros o categorías. Es la condición originaria y originante de todo pensar. De ahí que sea denominada como «apercepción originaria o apercepción trascendental» y mediante ella designamos la unidad de la conciencia en cada una de sus representaciones, la unidad de la multiplicidad intuitiva, o lo que es lo mismo, la unidad del objeto representado. Es autorreflexión y tiene la tarea de transformar nuestras condiciones subjetivas de conocer en conocimientos objetivos. Por todo ello, la tesis fuerte del idealismo trascendental kantiano afirmará lo siguiente:

Las condiciones de posibilidad de la experiencia en general constituyen, a la vez, las condiciones de posibilidad de los objetos de la experiencia y por ello poseen validez en un juicio sintético $a$ priori. ${ }^{15}$

En esta tesis se pone de manifiesto la identificación de la naturaleza humana (razón, conciencia, entendimiento, sensibilidad) consigo misma en el conocimiento de objetos externos e internos, ya que la conciencia es legisladora tanto del mundo interno como del mundo externo. Es la consecuencia genuina de haber llevado hasta el límite el giro copernicano: no nos importa lo que sean los objetos externos o internos, sino nuestro modo de concebirlos y determinarlos en conceptos expresables en juicios sintéticos a priori.

El despliegue de la subjetividad trascendental con sus categorías, esquemas y principios pone de manifiesto la fuerza de lo universal sobre lo particular, a saber, la fuerza de la conciencia sobre la afección de los objetos por los sentidos. De lo empírico-material, de lo contingente, sólo podemos hacer un discurso

$13 K r V \mathrm{~B} 140$.

$14 K r V \mathrm{~B} 132$.

$15 \quad K r V$ A $158 /$ B 197 
comunicable, si lo revestimos de elementos universales, acordes al género humano. La ciencia es de lo universal. En este sentido, la teoría kantiana del conocimiento ofrece un modelo perfecto, en el paradigma de la filosofía de la conciencia, de la tesis central de la epistemología contemporánea: no hay datos sino para teorías. Los hechos desnudos no existen, sólo existen interpretaciones. De ahí que Kant tenía razón cuando afirmaba que las leyes de la naturaleza (leyes de la física newtoniana) funcionaban porque habían sido puestas previamente por el entendimiento, esto es, por el investigador trascendental. La naturaleza no tiene leyes propias, sino que se comporta en conformidad con unas hipótesis puestas previamente por nuestra facultad de conocer.

En otras palabras, todos los fenómenos de la naturaleza tienen que someterse, en lo que a su combinación se refiere, a las categorías, de las cuales, como fundamento originario de la necesaria legalidad de la naturaleza (en cuanto natura formaliter spectata) depende ésta (considerada simplemente en cuanto naturaleza general). ${ }^{16}$

Parecería así como si el juego de la lógica trascendental impidiese al sujeto salir de sí mismo. De ahí la necesidad de la Crítica del Juicio. La reflexión kantiana sobre una nueva forma de conocer que va más allá de la razón teórica y de la razón práctica, a saber sobre el sentimiento de placer y displacer, conduce a la experiencia crítica, a un planteamiento radical acerca de la comunicabilidad de nuestras representaciones, de nuestros pensamientos y de nuestros juicios. Ese planteamiento se lleva a cabo en el núcleo de la Analítica de lo bello, al plantearse el problema de la comunicabilidad de los juicios de gusto.

\section{TRÁNSITO DE LA SUBJETIVIDAD TRASCENDENTAL A LA INTERSUBJETIVIDAD, DESDE LA CRÍTICA DEL GUSTO}

La tesis kantiana es que la razón por la que un juicio de gusto es comunicable es exactamente idéntica a la del juicio teórico, esto es, la adecuación entre imaginación y entendimiento, sólo que en el caso del juicio de gusto se establece una concordancia libre sin restricción a concepto alguno. Pero en ambos casos se postula la misma validez universal y, por tanto, la misma universal

16 KrV B165. Igualmente en Prolegómenos a toda metafísica futura que pueda presentarse como ciencia: "La mera forma universal de la intuición, que se llama espacio, es, pues, el sustrato de todas las intuiciones determinables como objetos particulares, y en aquel yace ciertamente la condición de la posibilidad y de la diversidad de las últimas; pero la unidad de los objetos es determinada únicamente por el entendimiento, y ello según condiciones que yacen en la naturaleza propia de éste; y así es el entendimiento el origen del orden universal de la naturaleza, puesto que abarca todos los fenómenos bajo las leyes propias de él, y con ello ya origina a priori, ante todo, una experiencia (según la forma), en virtud de la cual todo lo que haya de ser conocido por experiencia está sometido necesariamente a las leyes del entendimiento». (Kant, Prolegómenos...,Trad. Mario Caimi. Ed. Charcas, Buenos Aires 1984. pp. 90-91.) 
comunicabilidad. En el § 9 de la $K U$ dice Kant: «La universal comunicabilidad subjetiva del modo de representación en un juicio de gusto, debiendo realizarse sin presuponer un concepto, no puede ser otra cosa más que el estado de la mente (Gemützustand) en el libre juego de la imaginación y del entendimiento, en cuanto que estos concuerdan recíprocamente, como ello es necesario para un conocimiento en general $»^{17}$. Por tanto, el juicio de gusto, en cuanto tal, cumple las condiciones de objetividad de todo juicio sintético a priori, es comunicable universalmente porque el fundamento de su comunicabilidad está, como en cualquier otro juicio, en la armonía de nuestras facultades de conocer, en la cual descansa la validez universal subjetiva de la satisfacción que unimos con la representación estética de un objeto. Es por ello por lo que, el juicio de gusto, cuyo fundamento de determinación es meramente subjetivo, puede ser considerado como un juicio objetivo. Las pretensiones de universalidad y necesidad del juicio de gusto tienen su fundamento en las dos condiciones siguientes:

$1^{\text {a }}$. Referida al conocimiento en general: la objetividad del juicio de gusto tiene su fundamento en la universalidad de la naturaleza humana, en conformidad con la cual las condiciones subjetivas de juzgar en general deben ser idénticas en todos los seres humanos, hecho que viene corroborado por la superación del escepticismo.

$2^{\mathrm{a}}$. Referida al sentimiento de placer y displacer: para que un juicio de gusto pueda ser considerado como objetivo tiene que estar referido única y exclusivamente a las condiciones formales de la facultad de juzgar, esto es, a la relación entre imaginación y entendimiento, y además que tal juicio sea puro, esto es, que no esté mezclado ni con un concepto del objeto ni con sensaciones, como motivos de determinación del mismo.

Así pues, el Gusto ha de definirse como «la facultad de juzgar a priori la comunicabilidad de los sentimientos que están unidos con una representación dada, sin intervención de un concepto ${ }^{18}$. Ahora bien, en la fundamentación última de la comunicabilidad de los juicios de gusto, Kant remite a un principio general de comunicabilidad universal al que denomina Gemeinsinn (sentido común) y que se presenta como «la condición necesaria de la universal comunicabilidad de nuestro pensamiento, la cual, en toda lógica y en todo principio del conocimiento que no sea escéptico, ha de ser presupuesta ${ }^{19}$. Con tal principio designa Kant esa peculiar disposición y proporción que deben adoptar nuestras facultades de conocer en general en la constitución de cualquier conocimiento, ya sea teórico, práctico o estético. Que hay razones suficientes para postular tal principio o estructura como la condición trascendental de nuestros juicios, nos lo muestra el hecho mismo de que al menos algunos juicios son comunicables.

$17 K U$ § 9, 29 (A. K., V, 217-18).

$18 K U \S 40,161$ (A. K. V 296).

$19 K U \S 21,66$ (A. K. V 239). 
Como ya he mencionado anteriormente, para el filósofo trascendental, el hecho mismo de poder discutir acerca de la posibilidad del conocimiento es ya una superación de la actitud escéptica, porque lo que verdaderamente le importa es remontarse a las condiciones de posibilidad de la comunicabilidad del mismo. Pues bien, en el $\S 40$ de la $K U$ se explica el sensus communis del siguiente modo "la idea de un sentido que es común a todos, es decir, de una capacidad de juicio que, en su reflexión, tiene en cuenta por el pensamiento ( $a$ priori) el modo de representación de los demás para atener su juicio, por decirlo así, a la razón total humana y, así, evitar la ilusión que, nacida de condiciones privadas subjetivas, fácilmente tomadas por objetivas, tendría una influencia perjudicial en el juicio ${ }^{20}$.

De acuerdo con ello, postular el sensus communis como principio trascendental de la posibilidad del conocimiento significa apostar por una comunidad de diálogo intersubjetivo en la que el único requisito exigible para la comunicabilidad de nuestros juicios es el respeto a las máximas del entendimiento común humano que, como condiciones trascendentales hace suyas tanto el sensus communis logicus, cuanto el sensus communis aestheticus, a saber: pensar por sí mismo, pensar en lugar de cada otro, pensar siempre de acuerdo consigo mismo. Quien así juzga, nunca tomará la materia por la forma, ni el Erscheinung por el Phaenomenon, ni confundirá las condiciones privadas de una representación con las condiciones universales, sino que por el contrario siempre adoptará el punto de vista de lo universal. Y puesto que todo ser humano participa trascendentalmente de esas mismas condiciones de objetividad, el sensus communis aestheticus debe ser entendido como intersubjetividad ${ }^{21}$.

\section{De la SUbJETIVIDAD TRASCENDENTAL a LOS INTERESES DEL CONOCIMIENTO}

Ahora bien, ¿qué ha ocurrido en la Historia del pensamiento con la teoría trascendental del conocimiento? Después de Kant, las diversas experiencias que han acaparado el escenario filosófico en los dos últimos siglos han sido claramente kantianas o antikantianas. Es difícil encontrar un sistema filosófico que se haya mantenido completamente neutral, que se haya quedado al margen de la inflexión kantiana sobre la creatividad filosófica. Habermas ocupa un lugar privilegiado en esta historia.

El proyecto filosófico habermasiano es radicalmente kantiano en la medida en que se siente heredero de la racionalidad ilustrada y, por tanto, aboga por la

$20 K U \S 40,157$ (A. K. V 294).

21 Cfr. La excelente tesis doctoral presentada por Loyola CHÁvez, D. Hacia una filosofía de la comunidad política desde la Crítica del Juicio. Univ. de Comillas, 2015. Igualmente es verdaderamente interesante el libro de Cubo Ugarte, O., Kant. Sentido común y subjetividad. Ed. Plaza y Valdés, Madrid 2012. pp. 201-205. 
fuerza de una razón que teniendo en su horizonte la universalidad y la trascendentalidad, sin embargo, a la altura de su tiempo, sea preciso comprenderla como una razón sin trascendencia, esto es, situada en sus coordenadas espacio-temporales, una razón procedimental, es decir, preocupada por el procedimiento de construcción de las teorías científicas y una razón comunicativa, o lo que es lo mismo una razón lingüistizada, cuyo paradigma central es la intersubjetividad $^{22}$. Así, los sujetos capaces de lenguaje y acción que sobre el trasfondo de un mundo-de-la-vida se entienden entre sí sobre algo en el mundo, se sirven de la acción comunicativa y de la nueva experiencia que surge como producto de esa acción, en un proceso en el que la subjetividad trascendental se transfigura en una comunidad de sujetos que libre y críticamente buscan la intersubjetividad.

En su teoría de los intereses del conocimiento formulada en Conocimiento e interés a finales de los sesenta del pasado siglo, Habermas formula un proyecto kantiano de teoría del conocimiento a la altura de los tiempos. La tesis que defiende es la siguiente: el conocimiento no es, no puede ser, ni el acto contemplativo de un ente lógico-trascendental (Kant), ni tampoco lo puede ser la mera adaptación de un animal superior al medio natural y cultural (Pragmatismo), pero tiene que tener algo de ambos, tiene que ser una síntesis de contemplación y adaptación, de instinto gnóstico y de manipulación técnica, de teoría y praxis ${ }^{23}$. Trascendentalismo y pragmatismo se dan la mano allí donde el ser humano se autorrepresenta como un animal social e histórico. Habermas aboga por un pragmatismo trascendental. Gracias al conocimiento, la especie humana puede dominar la naturaleza y construir la ciudad socio-política, y ello sólo puede hacerlo desde construcciones universales. Así el conocer se presenta como un instrumento de la autoconservación en la medida en que trasciende a la mera autoconservación. En términos habermasianos, en un texto de clara resonancia kantiana, diríamos así: «Las condiciones de la actividad instrumental y comunicativa son al mismo tiempo las condiciones de la objetividad del conocimiento posible y por ello fijan el sentido de la validez de enunciados nomológicos y hermenéuticos» ${ }^{24}$. En este sentido, es preciso concebir la realidad trascendentalmente, desde tres categorías fundamentales, a saber: informaciones, interpretaciones y análisis, que en su vinculación con los intereses del conocimiento determinan la materialización habermasiana del sujeto trascendental kantiano ${ }^{25}$.

1. En primer lugar, mediante las informaciones ampliamos nuestra potencia de dominio técnico de la naturaleza. O lo que es lo mismo, mediante las

22 Habermas, J., Pensamiento postmetafísico. Trad. M. Jiménez Redondo. Ed. Taurus, Madrid 1990, pp. 45-62.

23 Habermas, J., Erkenntnis und Interesse (Mit einem neuen Nachwort), Suhrkamp, Francfort, 1973. Conocimiento e interés. Ed. esp. de M. Jiménez, J. F. Ivars y L. Martín Santo, Rev. por J. Vidal Beneyto. Ed. Taurus, 1982, p. 200 [en adelante $C I$ ].

${ }^{24}$ CI 213.

25 «Conocimiento e Interés» en Habermas, J., Ciencia y técnica como ideología. Trad. M. Jiménez y M. Garrido. Ed. Tecnos, Madrid 1986. pp. 175-176. 
teorías científicas, no solamente conocemos la naturaleza, como si de un mero instinto gnóstico se tratase, sino que gracias a la conversión de la ciencia en técnica y tecnología, ponemos la naturaleza al servicio de la especie humana. Por ello, afirmará Habermas que las ciencias empírico-analíticas están dirigidas por un interés técnico, un interés que no es meramente empírico-subjetivo, sino que es universal, históricotrascendental, es una orientación o guía de la especie humana en su propia historia.

2. En segundo lugar, mediante las interpretaciones, el conocimiento se nos presenta como tradición cultural en la que una sociedad se interpreta a sí misma gracias a la comunicabilidad del lenguaje ordinario. De ahí que las ciencias histórico-hermenéuticas estén dirigidas por un interés práctico. Su propósito va consistir en la conservación y ampliación de la intersubjetividad y comunicabilidad de las acciones humanas, y ello tanto desde el punto de vista vertical de las tradiciones comunes, como desde el punto de vista horizontal de las sociedades. El conocimiento, entendido como comprensión hermenéutica, tiene como propósito la búsqueda de un posible consenso entre los agentes en el marco de una autocomprensión transmitida.

3. En tercer lugar, mediante el análisis, el conocimiento se nos presenta como libertad, como capacidad de emancipación de la conciencia respecto de las fuerzas hipostasiadas. Las llamadas ciencias de la crítica están dirigidas por un interés emancipatorio y tienen como objeto orientar todas las acciones humanas, incluidas las ciencias empírico-analíticas y las ciencias histórico-hermenéuticas, hacia un propósito que podríamos especificar como la disolución crítica de las ilusiones objetivistas en los distintos saberes, así como el establecimiento de las bases para un comportamiento ilustrado tanto en el uso privado como en el uso público de la comunicación de los seres racionales libres.

De ese modo, la fundamental conexión entre conocimiento e interés sólo se producirá cuando el filósofo desarrolle su metodología como experiencia de la autorreflexión, esto es, como crítica a toda forma de positivismo, objetivismo o cosificación, esto es, como crítica a la comprensión objetivista de la ciencia, en la que se ha eliminado toda contribución de la subjetividad ${ }^{26}$. Este complejo programa de investigación ha sido llevado a cabo por Habermas en diálogo con los grandes filósofos de los siglos XIX y XX, Kant, Fichte, Hegel, Marx, Comte, Peirce, Dilthey, Freud, etc., pues a la altura de nuestro tiempo la experiencia filosófica tiene que ser desarrollada en su propia historia efectual. En diálogo con estas tradiciones, Habermas transformará, esto es, materializará, mundanizará el legado kantiano, pero siempre estará presente esa mirada trascendental que orienta la genuina experiencia filosófica.

26 CI 201. 
4. De los INTERESES DEL CONOCIMIENTO A LA RAZÓN COMUNICATIVA

El proyecto habermasiano es el resultado de una tensión fundamental entre su dependencia de la filosofía del sujeto o filosofía de la conciencia a través del concepto de autorreflexión y su dependencia del giro lingüístico a través del concepto de razón comunicativa. Ciertamente, esta tensión exime a sus lectores de tener que elegir entre Kant y Hegel, esto es, entre una razón descorporalizada convertida en una subjetividad constituidora del mundo(Kant) y la autorrealización de una razón historizada sometida a una teleología que se cierra circularmente sobre sí misma (Hegel). Más allá de Kant y Hegel, la experiencia filosófica habermasiana transfigura la razón trascendental y la razón historizada en una comunidad de sujetos que libre y críticamente buscan la intersubjetividad ${ }^{27}$.

Así, la razón comunicativa abre lingüísticamente un mundo de la vida, una comunidad de lenguaje en el que se producen todos los procesos de pensamiento. Los sujetos capaces de lenguaje y acción se comunican en el mundo de la vida a partir de una lengua, cuyo sistema de reglas incardina al individuo en las prácticas cotidianas de vida. El lenguaje se presenta así como una estructura de condiciones de posibilidad que deja su impronta en todas las consideraciones acerca de la realidad, pues esta se agota en el lenguaje. De este modo, el gradiente trascendental entre lo sensible-fenoménico y lo universal no ha de superarse en términos de Filosofía de la naturaleza o de Filosofía de la historia, sino que el nuevo escenario se debate entre la facticidad de los contextos vitales y la pretensión de una razón que, en cuanto lenguaje, no está dispuesta a renunciar ni un ápice a la autorreflexión, es decir, a la afirmación de la universalidad.

Esta nueva concepción de la racionalidad es el resultado de un proceso de transformación en el que son componentes esenciales el concepto de acción comunicativa -interacción mediada simbólicamente-, debido a George H. Mead, la noción de juegos de lenguaje de Wittgenstein y la teoría de los actos de habla de Austin y Searle. A partir de estos materiales y con el trasfondo de la teoría kantiana de la racionalidad, Habermas nos presenta una nueva concepción de la razón cuya característica peculiar consiste en su incardinación en el proceso cotidiano de comunicación lingüística.

La teoría de los actos de habla tiene como punto de partida la observación de que el empleo del lenguaje no consiste en la descripción de estados de cosas (ya sean afirmaciones, descripciones, narraciones), sino en cumplir por sí mismo una acción específica. Se trata de juicios que expresan autorizaciones, deseos, saludos, promesas, voliciones, etc. Tales usos del lenguaje no describen una realidad, sino que la generan, la producen. Así, todo acto de habla posee una estructura doble, a saber, la fuerza ilocucionaria (el acto de ordenar, prometer, preguntar, etc.) y el contenido proposicional (el núcleo semántico dotado de

$27 \quad$ CI 199. 
verdad). Realizar un acto de habla es comprometerse con una forma de conducta gobernada por reglas. De este modo, la doble estructura de los actos de habla -ilocucionaria y realizativa- conduce a los interlocutores al nivel de la intersubjetividad, en el que hablan entre sí acerca de objetos sobre los que se entienden. El posible éxito ilocucionario sólo se puede alcanzar de una manera cooperativa, esto es, mediante la interacción entre el hablante y el oyente, pues supone la asunción de una serie de compromisos que vinculan tanto al emisor como al receptor ${ }^{28}$.

Las condiciones que hacen posible la utilización del lenguaje no pertenecen a la esencia del lenguaje, sino a su pragmática, esto es, son inmanentes a la praxis comunicativa. De ahí que la problemática de la verdad se convierta aquí en el problema de las condiciones de aceptabilidad o las pretensiones de validez, que podemos formular así: un enunciado no es verdadero sólo porque corresponda a un determinado estado de cosas o porque resulte coherente con otros enunciados, sino que es declarado como verdadero si y sólo si a lo largo de un proceso argumentativo llega a ser aceptado bajo ciertas condiciones ideales. En ese sentido, para Habermas, todo usuario del lenguaje presupone en cada acto de habla una cuádruple pretensión de validez, a saber, la inteligibilidad, la veracidad o autenticidad, la verdad proposicional y la corrección o rectitud normativa. Quien realiza un acto de habla está ofreciendo a sus propios interlocutores un entendimiento (Verständigung) sobre algo que se da en su propia subjetividad (autenticidad), en el mundo objetivo (verdad proposicional) y en el mundo social-normativo (rectitud). Así, las tres funciones básicas del lenguaje - expresiva, cognitiva y apelativa - y sus correspondientes pretensiones de validez hacen referencia al mundo subjetivo de las vivencias privadas, al mundo objetivo de la totalidad de los hechos y al mundo intersubjetivo o social, regulado por normas comunes.

Se trata de la distinción entre pretensiones de validez (verdad, rectitud, veracidad) que los hablantes establecen con sus emisiones; entre mundos (objetivo, social, subjetivo), a los que el hablante se refiere con sus emisiones o manifestaciones; entre las actitudes básicas (objetivante, de conformidad con las normas, expresiva) que los hablantes adoptan y entre los que, en actitud

28 «He señalado ya cómo un acto de habla se compone de una oración realizativa y una oración subordinada de contenido proposicional. La oración principal se emplea en una emisión para establecer una relación intersubjetiva entre hablante y oyente; la oración subordinada se emplea en una emisión para comunicar sobre objetos (o estados de cosas). En la conexión elemental de la oración realizativa con una oración de contenido proposicional se muestra la doble estructura de la comunicación del lenguaje ordinario: una comunicación acerca de los objetos (o acerca de los estados de cosas) solo se produce a condición de una simultánea metacomunicación acerca del sentido en que se emplea la oración subordinada. Una situación de entendimiento posible exige que al menos dos hablantes/oyentes establezcan una comunicación simultáneamente en ambos planos: en el plano de la intersubjetividad en que los sujetos hablan entre sí, y en el plano de los objetos (o estados de cosas) sobre los que se entienden». Habermas, J., Teoría de la acción comunicativa: complementos y estudios previos. Trad. M. Jiménez Redondo. Ed. Cátedra, Madrid 1989, p. 83. [En adelante TACCEP] 
realizativa, pueden realizar tránsitos sin solución de continuidad y entre clases de actos de habla (constatativos, regulativos, representativos) que son indicadores de los modos puros de empleo del lenguaje (cognitivo, interactivo, expresivo). ${ }^{29}$

La intención de Habermas es poner de manifiesto que el uso originario o uso trascendental del lenguaje es aquel que está orientado al entendimiento de los individuos entre sí. Alcanzar un acuerdo o entendimiento entre las partes que participen en un proceso comunicativo es un fin inherente al lenguaje humano en general. Y así, los otros usos del lenguaje, ya sea el uso instrumental, el uso estratégico, el uso irónico, el uso impositivo, etc., son, en realidad, degradaciones del mencionado uso primario u original. Al servicio del lenguaje, el individuo participa necesariamente de la perspectiva social y deja en ese momento de estar anclado en la perspectiva egocéntrica, solipsista. La comunicación lingüística sólo tiene sentido en cuanto orientada al entendimiento con el otro, lo cual obliga al participante a cumplir las condiciones de racionalidad inmanentes a la acción comunicativa. Por tanto, toda acción lingüística es idealmente una acción orientada al entendimiento, y quien actúa en sociedad no puede sustraerse a esa idealidad ${ }^{30}$.

Ahora bien, el entendimiento (Verständigung) en cuanto telos inherente al lenguaje en su uso comunicativo representa tan sólo un fin que puede ser alcanzado o no. Por ello, las condiciones del entendimiento posible son meramente regulativas y no constitutivas. Y en esa línea de fundamentación, la Pragmática de Habermas no puede ser considerada como trascendental (al modo de K. O. Apel), sino sólo como formal o universal y puede quedar condensada en esta tesis: las condiciones del entendimiento posible coinciden con los presupuestos universales de la acción comunicativa, a los que pertenece el tipo de acción orientada al entendimiento, mientras que las otras formas de acción social sólo pueden considerarse como derivaciones o perversiones de la misma, ya pertenezcan al modelo de la acción estratégica, al modelo de negociación, al modelo de imposición, etc.

¿Cómo distinguir entre una comunicación auténtica orientada al entendimiento entre los participantes y una comunicación distorsionada o manipulada? Todo uso comunicativo del lenguaje presupone la aceptación de algunas reglas o condiciones mínimas y, por tanto, una situación hipotética que está en cierto modo anticipada e incluso es condición de posibilidad de todo discurso.

\section{TACCEP 462.}

30 Así, en el artículo fundacional de esta problemática «¿Qué significa pragmática universal?» (1976) dice Habermas: «La pragmática universal tiene como tarea identificar y reconstruir las condiciones universales del entendimiento posible. En otros contextos se habla también de presupuestos universales de la comunicación; pero prefiero hablar de presupuestos universales de la acción comunicativa porque considero fundamental el tipo de acción orientada al entendimiento» (TACCEP, 299). 
A esta situación contrafáctica Habermas la denomina situación ideal de habla ${ }^{31}$, cuyo estatuto onto-epistémico es equivalente al uso regulativo de las ideas de Kant o a la original position de John Rawls. Mediante ella, Habermas trata de salvaguardar la imparcialidad de las interacciones comunicativas, para lo cual es necesario cumplir estos tres requisitos: publicidad de las deliberaciones, reparto simétrico de los derechos de comunicación y estructuras libres de dominación ${ }^{32}$. Realmente son tres requisitos muy difíciles de alcanzar y se pueden resumir en uno, de inspiración peirceana: la peculiar coacción sin coacciones de los mejores argumentos ${ }^{33}$. Así pues, la situación ideal de habla debe excluir cualquier distorsión sistemática de la comunicación ${ }^{34}$.

Esta situación ideal de habla, materializada en la comunidad real e ideal de investigadores de cualquier rama de la ciencia, está estrechamente emparentada con la comunidad de discurso universal de George Mead, con la comunidad ideal de diálogo de K. O. Apel, con la comunidad de seres inteligentes y el concepto de final opinion de Peirce, con el concepto de Gemeinsam (comunidad) de W. Dilthey y, por supuesto, con la noción kantiana de sensus communis. En último término, la situación ideal de habla es en el movimiento del pensamiento la última figura de la conciencia trascendental. En este sentido, ha de ser entendida como un principio regulativo y no como un principio constitutivo que haya de ser realizado en la historia. No se trata de una utopía concreta sino de un criterio universal de comunicación mediante el que se puede juzgar hasta qué punto los participantes de un diálogo están dispuestos a aproximarse a un acuerdo,

31 «Mi explicación es que los participantes en la argumentación suponen en común algo así como una situación ideal de habla. La situación ideal de habla vendría determinada porque todo consenso que pueda alcanzarse bajo sus condiciones, puede considerarse per se un consenso racional. Mi tesis es pues: la anticipación de una situación ideal de habla es lo que garantiza que podamos asociar a un consenso alcanzado fácticamente la pretensión de ser un consenso racional» (TACCEP, 105).

32 Cfr. Velasco, J. C., Habermas. El uso público de la razón. Alianza Editorial, Madrid, 2013 , p. 58.

33 Recordemos que para Peirce una verdad científica consiste en una información sobre cuya validez se puede alcanzar un consenso no-coactivo y permanente que, sin ser definitivo, apunta sin embargo a dicha condición definitiva como su meta: "La investigación se distingue en principio, de los otros métodos, en que la naturaleza de la conclusión final a la que conduce está, en cada caso, predeterminada, desde el primer momento, sin relación alguna con el estadio inicial de la opinión. Si dejamos que dos hombres investiguen, con independencia uno del otro, una cuestión cualquiera y con la única condición de que lleguen suficientemente lejos dicha investigación, llegarán a un acuerdo que en modo alguno se verá ya afectado porque prosiga la investigación». "The Logic of 1873» en Collected Papers of Charles Sanders Peirce, vols. VII-VIII. Ed. De Arthur W. Burks, Cambridge. Harvard University Press 1966, p. 319.

34 «Llamo ideal a una situación de habla en que las comunicaciones no solamente no vienen impedidas por influjos externos contingentes, sino tampoco por las coacciones que se siguen de la propia estructura de la comunicación. La situación ideal de habla excluye las distorsiones sistemáticas de la comunicación. Y la estructura de la comunicación deja de generar coacciones solo si para todos los participantes en el discurso está dada una distribución simétrica de las oportunidades de elegir y ejecutar actos de hablar». (TACCEP, 153). 
a un consenso motivado por la coacción sin coacciones del mejor argumento. De ahí que, a pesar de todas sus limitaciones, la razón comunicativa posea una serie de ventajas con respecto a todos aquellos discursos que prometen la emancipación de la Humanidad, ya sea en este mundo o en el otro. La razón comunicativa no ofrece ni redención ni consuelo, sino que se siente satisfecha con facilitar la posibilidad, nunca garantizada, de una reconciliación política y social mediante el uso público de la razón, esto es, mediante el ejercicio de los derechos de deliberación, participación y comunicación en el ámbito de la esfera pública ${ }^{35}$.

La razón comunicativa como singular pensamiento postmetafísico adopta una marcada perspectiva finita, inmanente y secularizada. Ello significa una renuncia pública a ser entendida como una razón absoluta, incluida la renuncia a intentar imponer dogmáticamente su propia concepción del ideal del proceso comunicativo. En definitiva, al modo del noúmeno kantiano, la situación ideal de habla habermasiana debe ser entendida como un discurso utópico negativo, por la dificultad de instaurar en la Historia ese modelo puro de asociación comunicativa, pero justamente por ello ha sido uno de los motores, desde luego no el único, que ha hecho posible el progreso técnico, científico y moral de la Humanidad.

Universidad Complutense de Madrid Antonio M. López MoLina amlm@filos.ucm.es

[Artículo aprobado para publicación en febrero de 2020]

35 Velasco, J. C. O. cit. p. 62. 